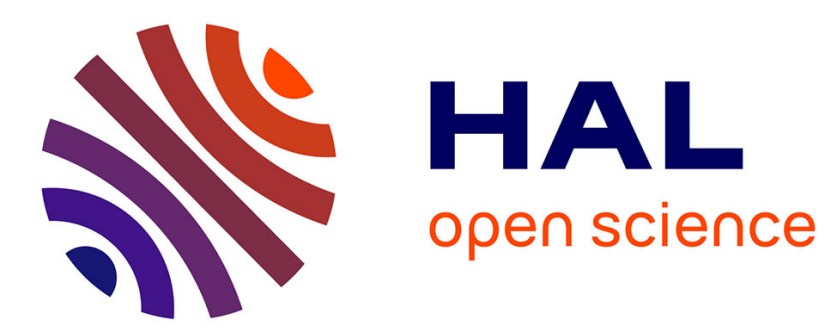

\title{
ATOM-PROBE STUDY OF SOME FINE-SCALE FEATURES IN NICKEL BASE SUPERALLOYS
}

\author{
A. Buchon, A. Bostel, D. Blavette
}

\section{To cite this version:}

A. Buchon, A. Bostel, D. Blavette. ATOM-PROBE STUDY OF SOME FINE-SCALE FEATURES IN NICKEL BASE SUPERALLOYS. Journal de Physique Colloques, 1989, 50 (C8), pp.C8-401-C8-406. 10.1051/jphyscol:1989868 . jpa-00229966

\section{HAL Id: jpa-00229966 https://hal.science/jpa-00229966}

Submitted on 1 Jan 1989

HAL is a multi-disciplinary open access archive for the deposit and dissemination of scientific research documents, whether they are published or not. The documents may come from teaching and research institutions in France or abroad, or from public or private research centers.
L'archive ouverte pluridisciplinaire HAL, est destinée au dépôt et à la diffusion de documents scientifiques de niveau recherche, publiés ou non, émanant des établissements d'enseignement et de recherche français ou étrangers, des laboratoires publics ou privés. 
ATOM-PROBE STUDY OF SOME FINE-SCALE FEATURES IN NICKEL BASE SUPERALLOYS

\author{
A. BUCHON, A. BOSTEL and D. BLAVETTE \\ Laboratoire de Microscopie Ionique, URA CNRS 808, BP. 118, F-76134 Mont \\ Saint Aignan Cedex, France
}

\begin{abstract}
A single crystal nickel base superalloy (CMSX-2) has been investigated by means of atom-probe techniques. The relationship between applied heat treatments and the composition of both $\gamma$ and $\gamma^{\prime}$ phases are studied. The role of each precipitation sequence in the standard heat treatment $\left(1050^{\circ} \mathrm{C} / 16 \mathrm{~h}+850^{\circ} \mathrm{C} / 48 \mathrm{~h}\right.$ air cool) is discussed. The high spatial resolution of the atom-probe is used for the investigation of the fine scale concentration fluctuations which may occur in the $r$-solid solution. The microanalyses exhibit concentration modulations for chromium; the wavelength is close to $25 \AA$. The spatial convolution effects of sine-like fluctuations with the analysis area are discussed.
\end{abstract}

\title{
I. Introduction
}

The design of new aircraft engines with a higher efficiency relies on the increase of both the turbine entry temperature and the rotating speed. For this purpose, new generations of nickel base superalloys like single crystal materials have been developed for turbine blades. The material we investigated, namely CMSX-2 alloy, belongs to this new class of superalloy.

Nickel base superalloys derive their excellent creep performances from the presence of a high volume fraction of $\gamma^{\prime}$ ordered particles the composition of which is based on $\mathrm{Ni}_{3} \mathrm{Al}$. High temperature $\left(1000^{\circ} \mathrm{C}\right)$ properties of these materials are closely connected with the lattice misfit between the solid solution $\boldsymbol{\gamma}$ and $\boldsymbol{\gamma}^{\prime}$ precipitates. It is therefore of utmost importance to get a better understanding of relationships between applied heat treatments and phase composition which in turn controls the $\gamma-\gamma^{\prime}$ misfit. More subtle effects are also interesting to investigate. For instance, local concentration gradients near $\gamma-\gamma^{\prime}$ interfaces [1], [2], or the occurrence of clusters in the $r$ matrix [3], have been already reported and shown to have an influence on mechanical properties. Slight segregation of minor elements like boron or carbon at some of the $\gamma-\gamma^{\prime}$ interfaces were also observed in Udimet 720 [4]. In contrast, APFIM studies of a high chromium superalloy IN939, revealed no detectable segregation of refractory elements like $W$ and $T a$ to the $Y-\gamma^{\prime}$ coherent interfaces $[5]$.

The aim of this study is to investigate the single crystal nickel base superalloy CMSX-2 by using time of flight atom probe techniques. The studies we have undertaken are focused towards the relationship between the microchemistry of these materials and the applied heat treatments. The spatial distribution of solute elements in the $r$ matrix will also be studied in detail. 


\section{Experimental}

The nominal composition of CMSX-2 is given in Table 1. The (001) oriented single crystals we used in this study, were provided by the ONERA.

The material was subjected to a standard three-step heat treatment which consists in a one stage solution treatment $\left(1315^{\circ} \mathrm{C} / 30 \mathrm{mn}\right.$, air cool) followed by a sequence of two aging treatments $\left(1050^{\circ} \mathrm{C} / 16 \mathrm{~h}\right.$, air cool $+850^{\circ} \mathrm{C} / 48 \mathrm{~h}$, air cool). This standard heat treatment leads to (001) well aligned cuboidal precipitates with a size close to $0.45 \mu \mathrm{m}$. The volume fraction is $70 \%$. As shown by CARON and KHAN [6], this regular microstructure improves creep performances: APFIM specimens were cut from the bulk and (001) oriented tips were prepared by standard electropolishing techniques.

Major atom-probe experiments were performed using a high pulse fraction (20\%) and low temperatures $(40 \mathrm{~K})$ in order to prevent preferential evaporation of nickel atoms from interfering. Low detection flux $(<0.05$ ion/pulse) was maintained in such a way to minimize pile-up effects. Figure 1 illustrates the field evaporation behaviour of (001) planes in the $\gamma$ solid solution. Glose examination of both the flux curve and the related composition profiles reveals the evaporation sequence in each plane : nickel atoms field evaporate before chromium atoms. This observation is in good agreement with both the preferential evaporation of nickel and the lower stability of nickel rich (001) planes in $\boldsymbol{\gamma}^{\prime}$ we already observed in superalloys [7].

\begin{tabular}{|c|c|c|c|c|c|c|c|c|}
\hline $\begin{array}{c}\text { element } \\
\text { at \% }\end{array}$ & A1 & Ti & Cr & Ni & Co & Ta & W & Mo \\
\hline $\begin{array}{c}\text { Atom-probe } \\
\text { data }\left(\mathrm{F}_{\vee}=70 \%\right)\end{array}$ & 12.5 & 1.2 & $\mathbf{1 0 . 5}$ & 65.4 & 5.1 & 2.1 & 2.8 & 0.3 \\
\hline $\begin{array}{c}\text { Manufacturer } \\
\text { (ONERA) }\end{array}$ & 12.5 & 1.2 & 9 & 67.4 & 5 & 2 & 2.5 & 0.4 \\
\hline
\end{tabular}

Table 1 : nominal composition of CMSX-2 as given by the manufacturer and overall concentrations as measured by atom-probe analyses

\section{Results}

In order to clarify the role of each precipitation sequence in the standard heat treatment, we have investigated the superalloy CMSX-2 in the following conditions : $1315^{\circ} \mathrm{C} / 30 \mathrm{mn}$ Air cooled $+1050^{\circ} \mathrm{C} / 16 \mathrm{~h}$ water quenched. This treatment corresponds to the first aging stage of the standard heat treatment.

A typical concentration profile is given figure 2. As cuboidal precipitates have their sides parallel to (100) planes, microanalyses of (001) oriented tips are frequently conducted in a direction which is perpendicular to $\boldsymbol{\gamma}-\boldsymbol{\gamma}^{\prime}$ interfaces. Both chromium and aluminium concentration profiles reveal an abrupt interface between a coarse primary precipitate and the $\gamma$ solid solution. After aging at $1050^{\circ} \mathrm{C}$, the material was rapidly quenched in such a way to prevent $\gamma^{\prime}$ forming elements to precipitate onto existing primary particles. The aluminium profile clearly demonstrates that small secondary precipitates $(50-100, \AA)$ form in the $Y$ matrix during cooling. This means that the supersaturation has been released without increasing the initial volume fraction of large primary precipitate in a large extent. As a consequence, the overall composition of the solid solution (including 
fine secondary precipitates) is probably very close to the equilibrium one at $\mathrm{T}=1050^{\circ} \mathrm{C}$. This should be also true for primary $\gamma^{\prime}$ precipitates. Tables 2 and 3 summarize phase composition as measured by atom-probe techniques for this heat treatment $\left(1050^{\circ} \mathrm{C} / 16 \mathrm{~h}\right)$.

\begin{tabular}{|c|r|c|c|r|c|c|c|c|}
\hline element at $\%$ & \multicolumn{1}{c|}{ Al } & Ti & Cr & Ni & Co & Ta & W & Mo \\
\hline $1050^{\circ} \mathrm{C} / 16 \mathrm{~h}$ & 16.3 & 1.3 & 3.2 & 69.3 & 4.5 & 2.7 & 2.4 & 0.3 \\
water quenched & \pm 0.4 & \pm 0.1 & \pm 0.2 & \pm 0.5 & \pm 0.2 & \pm 0.2 & \pm 0.2 & \pm 0.1 \\
\hline $1050^{\circ} \mathrm{C} / 16 \mathrm{~h}$ & 16.7 & 1.6 & 2.7 & 70.0 & 3.3 & 2.8 & 2.6 & 0.2 \\
$+850^{\circ} \mathrm{C} / 48 \mathrm{~h}$ & \pm 0.6 & \pm 0.2 & \pm 0.3 & \pm 0.7 & \pm 0.3 & \pm 0.3 & \pm 0.3 & \pm 0.1 \\
Air cooled & & & & & & & & \\
\hline
\end{tabular}

Table 2 : composition of $r^{\prime}$ precipitates for the two heat treatments

\begin{tabular}{|c|c|c|c|c|c|c|c|c|}
\hline$t$ at $\%$ & Al & $\mathrm{Ti}$ & $\mathrm{Cr}$ & $\mathrm{Ni}$ & Co & $\mathrm{Ta}$ & $\mathrm{W}$ & Mo \\
\hline $\begin{array}{c}1050^{\circ} \mathrm{C} / 16 \mathrm{~h} \\
\text { water quenched }\end{array}$ & $\begin{array}{r}6.1 \\
\pm 0.4\end{array}$ & $\begin{array}{r}0.4 \\
\pm 0.1\end{array}$ & $\begin{array}{r}20.6 \\
\pm 0.6\end{array}$ & $\begin{array}{r}58.3 \\
\pm \quad 0.7\end{array}$ & $\begin{array}{r}9.3 \\
+0.4\end{array}$ & $\begin{array}{r}0.8 \\
+0.1\end{array}$ & $\begin{array}{r}4.2 \\
\pm 0.3 \\
\end{array}$ & $\begin{array}{r}0.4 \\
\pm 0.1\end{array}$ \\
\hline $\begin{array}{r}1050^{\circ} \mathrm{C} / 16 \mathrm{~h} \\
+850^{\circ} \mathrm{C} / 48 \mathrm{~h} \\
\text { Air cooled }\end{array}$ & $\begin{array}{r}2.8 \\
+0.2\end{array}$ & $\begin{array}{r}0.3 \\
+0.1\end{array}$ & $\begin{array}{r}28.8 \\
\pm 0.5\end{array}$ & $\begin{array}{r}54.6 \\
\pm 0.5\end{array}$ & $\begin{array}{r}9.2 \\
+0.4\end{array}$ & $\begin{array}{r}0.5 \\
+0.1\end{array}$ & $\begin{array}{r}3.2 \\
\pm 0.2 \\
\end{array}$ & $\begin{array}{r}0.6 \\
\pm 0.2\end{array}$ \\
\hline
\end{tabular}

Table 3 : composition of the $\gamma$ matrix Atom probe data include secondary particles for the one-step heat treatment $\left(1050^{\circ} \mathrm{C} / 16 \mathrm{~h}\right)$

The composition of $\gamma$ and $\gamma^{\prime}$ for the standard heat treatment $\left(1050^{\circ} \mathrm{G} / 16 \mathrm{~h}+\right.$ $850^{\circ} \mathrm{C} / 48 \mathrm{~h}$ ) is also given in tables 2 and 3 for comparison. Atom probe data show that the composition of primary $\gamma^{\prime}$ particles does not vary in a large extent with aging temperature. The standard heat treatment produces a monomodal dispersion of $\gamma^{\prime}$ the composition of which should be close to that of equilibrium $\gamma^{\prime}$ precipitates at $T=850^{\circ} \mathrm{C}$. In contrast, Table 2 clearly reveals that the composition of $\gamma$ matrix is strongly dependent on the heat treatment. As expected, the limit of solubility of aluminium in $\boldsymbol{\gamma}$ is observed to increase with temperature whereas the chromium content decreases. These observations are in good agreement with that of HOPGOOD et al [1] who performed APFIM investigations on a similar single crystal superalloy (SRR 99).

By using the lever rule, the volume fraction of small $\gamma^{\prime}$ existing in the matrix of the one-step aging treatment, may be estimated. The calculations shows that both Al and Cr content in $\gamma$ for $T=1050^{\circ} \mathrm{C}$ lead to a volume fraction $F_{v}$ close to $7 \%$. The phase composition for the standard heat treatment is consistent with the nominal composition as given by the manufacturer (table 1) for a volume fraction close to $70 \%$. However, small deviations, have been detected for chromium. The concentration of this element in $\gamma$ matrix was found to vary from one region to another, typically from 25 at $\%$ to 30 at $\%$

As discussed in the introduction, the occurrence of small clusters or concentration fluctuations in the solid solution may influence high temperature properties of nickel base superalloys. As a result, we have investigated the spatial distribution of solute elements in the $r$ matrix of the material which; was subjected to the standard treatment. The clearest trend we observe in CMSX-2, is the occurrence of fine scale modulations of chromium in the solid solution. As shown in figure 3 , concentration fluctuations are detected for chromium with a wavelength close to $25 \AA$; the 1 ateral resolution is around $10 \AA$. The various statistical tests (chi-squared tests) [8] we 
performed on our data, demonstrate that these chromium modulations are associated to a systematic trend. The amplitude of chromium fluctuations is close to $10 \%(15-35$ at \% see fig 3). Similar fine-scale modulations were also observed for chromium in other experiments conducted on single-phase materials the composition $(22.5$ at $\% \mathrm{Cr}$ ) of which is close to that of the $r$ matrix of CMSX-2. A concentration profile obtained for a material aged at $850^{\circ} \mathrm{C}$ for $768 \mathrm{~h}$ is presented in figure 4. The related Fourier transform provided in figure 5 , again exhibits the emergence of a wavelength around $25 \AA$. It is important to notice that these fine-scale fluctuations are often difficult to be detected in the experiments which were performed with a low lateral resolution. When the analysis area has, for instance, a diameter $\left(\Phi_{a}\right)$ greater than $15 \AA$, the observed amplitudes ( $A^{*}$ ) get more and more attenuated because of the unavoidable radial convolution of fluctuations $(\lambda=25 \AA)$ with the analysis cylinder. For three-dimensional sinusoidal fluctuations (with an amplitude equal to $A$ ), one can qualitatively estimate the compression factor of amplitudes (G) as follows :

$$
G \approx\left[\frac{\sin \pi \Phi_{\mathrm{a}}^{\prime} / \lambda}{\pi \phi_{\mathrm{a}}^{\prime} / \lambda}\right]^{2} \text { with } G=A^{*} / A \text { and } \Phi_{\mathrm{a}}^{\prime}=\phi_{\mathrm{a}} \sqrt{\pi} / 2
$$

This rudimental calculation provides a rough estimation of the attenuation factor (G) for $\phi_{a}=15 \AA$ close to 0.35 . Similarly, the smoothing techniques, often used in concentration profiles, lead to an additional axial convolution. Again, the measured amplitudes $\left(A^{*}\right)$ are attenuated; for a sine-like signal $\left(C=C_{0}+A \sin 2 \pi x / \lambda\right)$ smoothed over a depth $(\Delta)$, the attenuation factor $(F)$ writes :

$$
F=\frac{\sin \pi \Delta / \lambda}{\pi \Delta / \lambda} \quad \text { with } F=A^{*} / A
$$

As a result, the use of a high spatial resolution $\left(\phi_{a}\right)$ reduces lateral convolution effects but may lead to an enhanced axial convolution. When $\phi_{a}$ is small (10 $\AA$ for instance) the reduced number of ions per layer ( 4 ions $/ \AA$ ) often requires a large smoothing window ( $\Delta$ ) in order to ensure a reasonable number (N) of ions per sampling block (for $\mathrm{N}=50$ ions/block, $\Delta=12.5 \AA(\lambda / 2)$ so that $F \simeq 0.64$ for $\lambda=25 \AA$ ).

Finer effects concerning Al distribution were detected with the help of concentration histograms and were confirmed by the chi-squared tests we made. This very subtle trend for Al to form clusters is however difficult to see in concentration profiles.

\section{Conclusion}

The investigations we conducted on the influence of heat treatments clearly show that the second aging treatment $\left(850^{\circ} \mathrm{C} / 48 \mathrm{~h}\right)$ leads to a volume fraction of primary particles $7 \%$ higher than the observed value at $1050^{\circ} \mathrm{C}$. In the standard heat treatment, the material is not quenched but simply air cooled. After the first precipitation sequence $\left(1050^{\circ} \mathrm{C} / 16 \mathrm{~h}\right)$, due to the supersaturation of $\gamma, \gamma^{\prime}$-forming elements in excess diffuse toward existing primary $\gamma^{\prime}$ particles. This produces an increase in the volume of primary precipitates. Subsequent aging at $850^{\circ} \mathrm{C}$ for $48 \mathrm{~h}$ followed by an air cooling to room temperature leads to an overall volume fraction of precipitates close to $70 \%$.

The high spatial resolution microanalyses we conducted, have shown that fine scale chromium fluctuations occur in the matrix of the standard material. The Fourier transforms (Figure 5) as well as autocorrelations we applied to chromium concentration profiles showed that the signal is composed of various Fourier components. The predominant wavelength of 
these modulations is close to $25 \AA$ and the amplitude of concentration fluctuations is about $10 \%\left(c_{c r}^{\circ} \pm 10 \%\right)$.

Recently, SCHONFELD et al [9] investigated the binary alloy Ni-19.4 at \% Cr by diffuse neutron scattering. The authors proposed to interprete the short-range order scattering pattern they observed by concentration waves of "imperfectly ordered clusters" the composition of which could be based on $\mathrm{Ni}_{2} \mathrm{Cr}$. As short range order is known to influence mechanical properties in solid solutions, it is thought that the chromium fluctuations we observed in the $\gamma$ matrix of the superalloy CMSX-2 should intervene in the material performances.

Acknowledgements: The single-crystal nickel base superalloys we studied were kindly provided by the office National de Recherches en Aéronautique (ONERA). We wish to thank Dr T. KHAN and P. CARON for the fruitful discussions we had. These researches were financially supported by the Direction des Recherches et Etudes Techniques (DRET) we would like to thank (Contract $n^{\circ} 87 / 031$ ).

\section{References}

[1] A.A. HOPGOOD, A. NICHOLLS, G.D.W. SMITH and J.W. MARTIN - Mat. Sci. and Techn. 4 (1988) $146-152$

[2] D. BLAVETTE, P. GARON and T. KHAN - Superalloys 88, The Metallurgical Society, (1988) $305-314$

[3] D. BLAVETTE, P. CARON and T. KHAN - Scripta Met, , 20 (1986) 1395-1405

[4] K.L. MORE and M.K. MILLER - J. de Phys. C6-49 (1988) 391-396

[5] K.M. DELARGY and G.D.W. SMITH - Met. Trans. 14A (1983) 1771-1783

[6] P. CARON and T. KHAN - Mater. Sci. Eng. 61 (1983) 173-184

[7] D. BLAVETTE and A. Bostel - Acta Met., 32 (1984) 811-816

[8] P. AUGER, A. MENAND and D. BLAVETTE - J. de Phys., C6-49 (1988) 439-445

[9] B. SHONFELD, F. KLAIBER, G. KOSTORZ, U. ZAUNE and G. MAINTYRE - Scripta Met., 20 (1986) 385-387

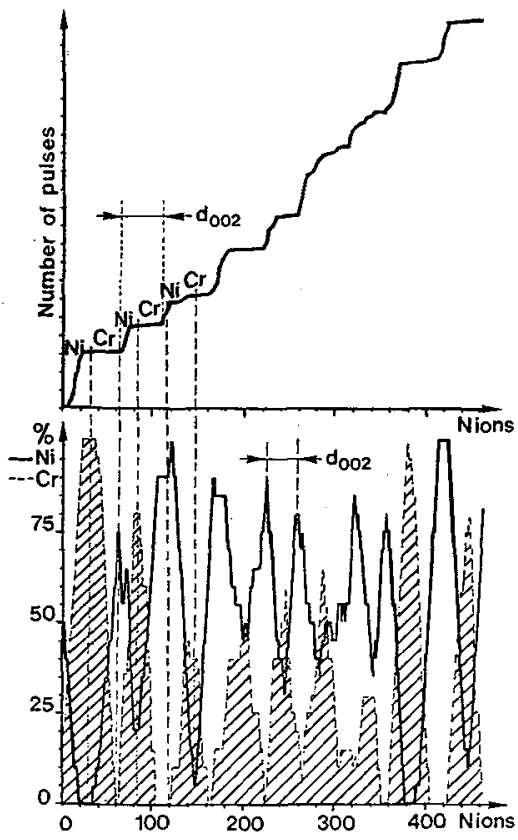

Figure 1 : Field evaporation behaviour of (001) planes in the pseudo-binary $\mathrm{Ni}-\mathrm{Cr}$ alloy ( $r$ phase) : concentration profiles and the related step. like flux curve (number of applied evaporation pulses as a function of the number of collected ions (abscissa)) clearly demonstrate that nickel desorbs first in each (001) plane. chromium evaporates upon the completion of each evaporation sequence. 
CMSX_2

$1315^{\circ} \mathrm{C} / 30 \mathrm{~min}+1050^{\circ} \mathrm{C} / 16 \mathrm{~h}+$ water quenched
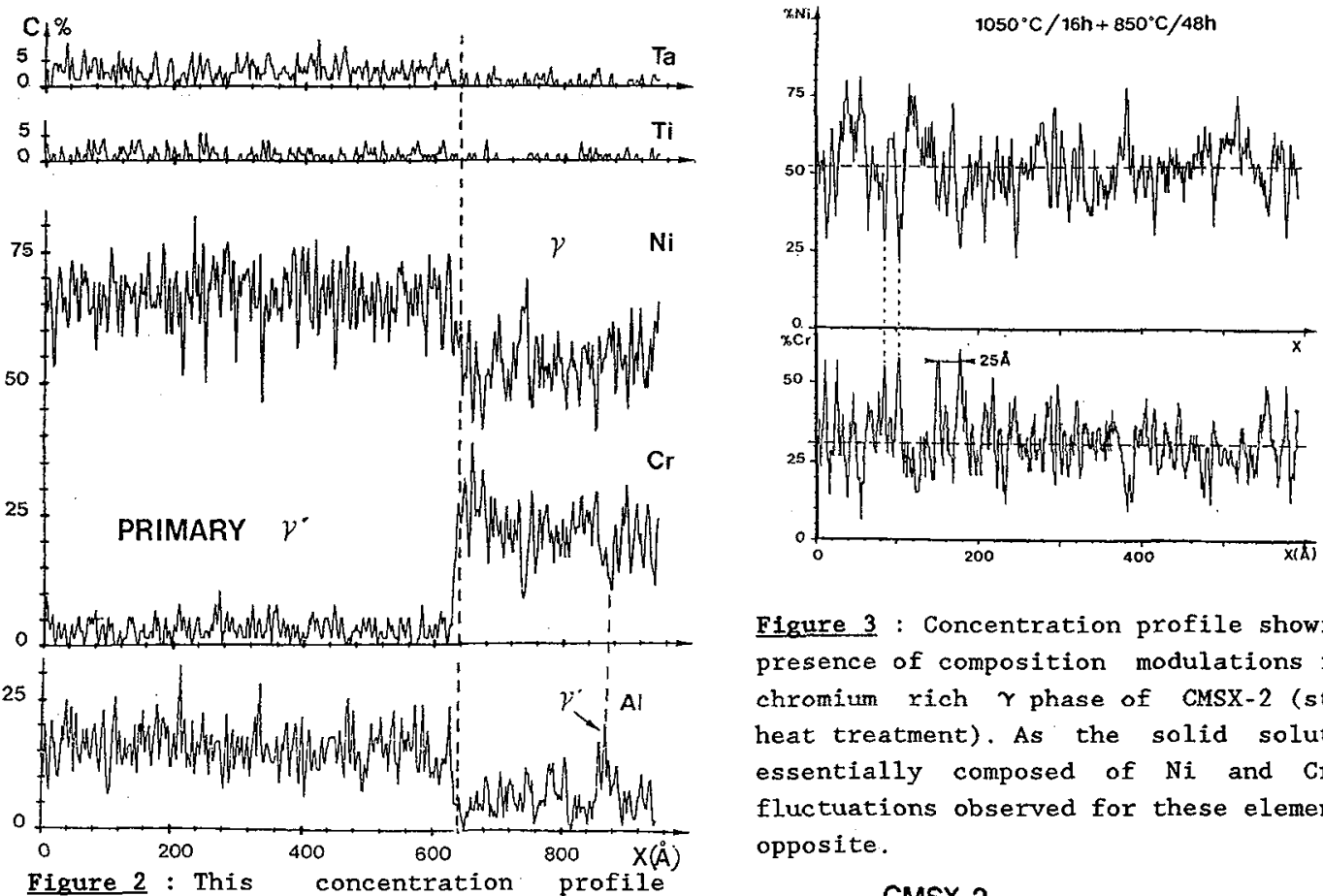

Figure 3 : Concentration profile showing the presence of composition modulations in the chromium rich $\gamma$ phase of CMSX-2 (standard heat treatment). As the solid solution is essentially composed of $\mathrm{Ni}$ and $\mathrm{Cr}$, the fluctuations observed for these elements axe opposite.

exhibits the presence of fine metastable secondary $r^{\prime}$ precipitates (Al rich phase) in the vicinity of a large primary particle. The CMSX-2 superalloy has been subjected to a single aging heat treatment $\left(1050^{\circ} \mathrm{C} / 16 \mathrm{~h}\right)$ followed by a water quench.

\section{CMSX_2}
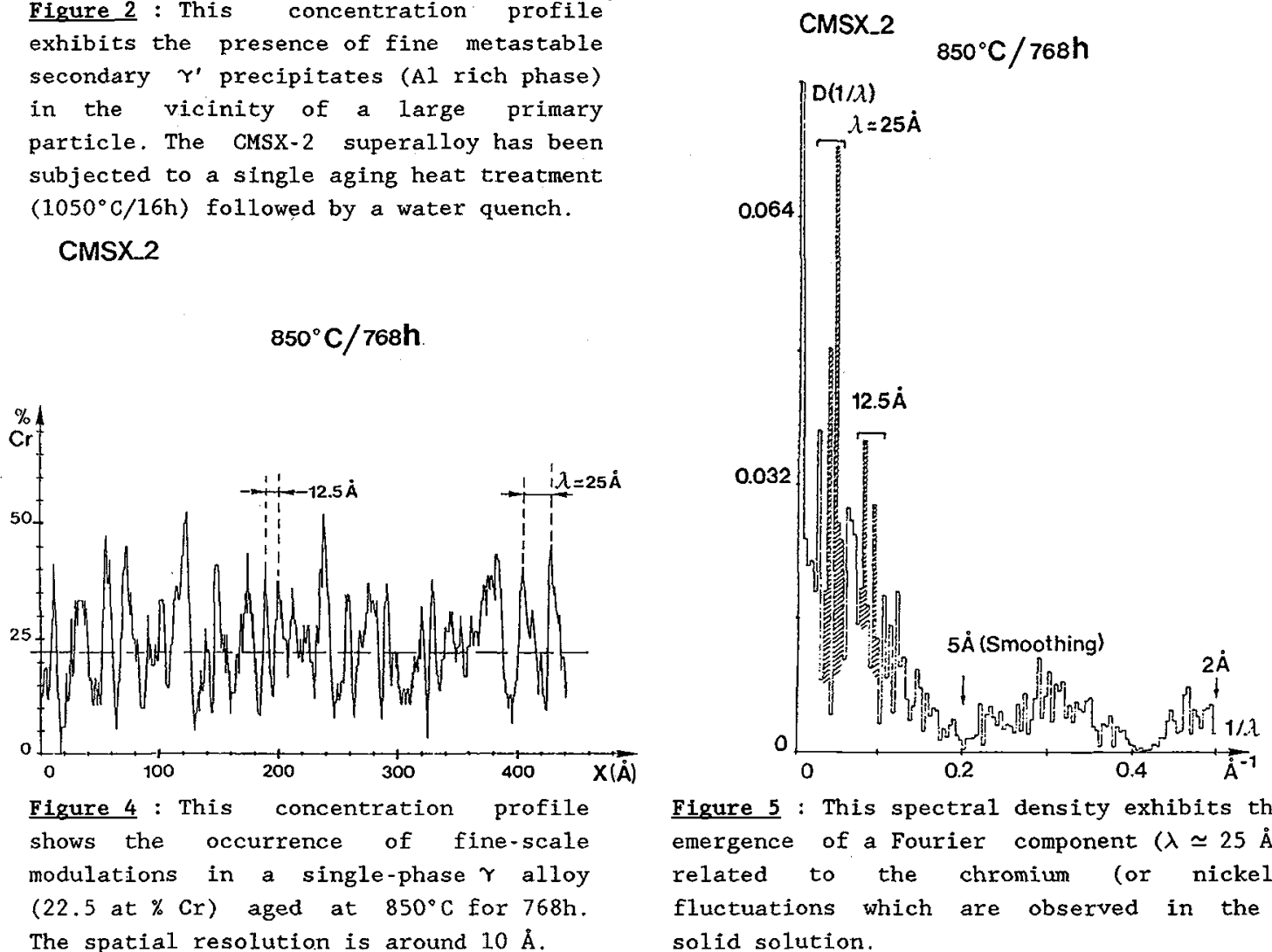

Figure 5 : This spectral density exhibits the emergence of a Fourier component $(\lambda \simeq 25 \AA)$ related to the chromium (or nickel) fluctuations which are observed in the $r$ solid solution. 